\title{
CHANGES IN THE ZIRCONIUM LOCAL SURROUNDING ON LIGAND SUBSTITUTION IN SOLUTIONS
}

\author{
V. V. Kanazhevskii, ${ }^{1,2}$ V. P. Shmachkova, ${ }^{2}$ \\ N. S. Kotsarenko, ${ }^{2}$ V. N. Kolomiichuk, ${ }^{2 \dagger}$ \\ and D. I. Kochubei ${ }^{2}$
}

UDC 541.8:544.3:544.17

EXAFS and SAXS methods have been used to examine zirconium hydroxide and oxychloride aqueous solutions in the presence of sulfuric acid in a wide range of concentrations, as well as a zirconium sulfate aqueous solution. The structure of the complexes and their transformation regularities were determined. Structures of the given complexes and structures of zirconium hydroxide and zirconium oxychloride and hydroxide complexes in aqueous solutions were compared. Complexes in zirconium hydroxide and oxychloride aqueous solutions have identical structures in the presence of sulfuric acid. When the concentration ratio of sulfuric acid and the initial compound is low (20-30), the complex is an open trimer with zirconium atoms bonded by sulfate groups. Bridge sulfate groups form $\mathrm{Zr}-\mathrm{O}-\mathrm{S}-\mathrm{O}-\mathrm{Zr}$ bonds. Apart from the bridge sulfate groups, there are three terminal sulfate groups and three terminal hydroxyl groups for each zirconium atom. When the concentration of sulfuric acid is increased (up to a ratio of 40-100), closed trimers are observed in the solution.

Keywords: zirconium hydroxide, zirconium oxychloride, zirconium sulfate, aqueous solutions of zirconium salts, sulphate solutions of zirconium salts, zirconium complexes, small-angle X-ray scattering, EXAFS.

\section{INTRODUCTION}

Zirconium oxide is the basis for ceramic materials and also finds its application in catalysis, electrochemistry, hightemperature fuel cells, and radioactive waste disposal. Aqueous solutions of inorganic zirconium salts are used, as a rule, in the synthesis of target products. It is known that zirconium makes complexes in aqueous solutions. Such factors as zirconium concentration, anion nature and solution $\mathrm{pH}$ affect their states. In the case of modifying zirconium oxide by another anion and/or cation, that is typical in the formation of zirconium ceramics and catalysts, the interaction between the initial complexes and added components takes place yielding new complexes. It is known that all these factors result in the structure modifications of the zirconium oxide structure, stabilization of new phases, and changes in electroconductivity, piezo properties, morphology, and mechanical characteristics. To determine the possibilities of managing the synthesis of the material with some specified properties, first of all, it is necessary to study the composition, structure, and stability of complexes in solutions.

\section{${ }^{\dagger}$ Deceased.}

${ }^{1}$ Novosibirsk State University. ${ }^{2}$ G. K. Boreskov Institute of Catalysis, Siberian Division, Russian Academy of Science, Novosibirsk; kochubey@catalysis.nsk.su. Translated from Zhurnal Strukturnoi Khimii, Vol. 47, No. 5, pp. 874-881, September-October, 2006. Original article submitted December 2, 2005. 
The structure of inorganic zirconium complexes in oxychloride, oxynitrate, and sulfate aqueous solutions was established earlier (see [1] and references therein). When sulfuric acid is added to inorganic salt solutions, other zirconium complexes are formed. In acid solutions at different concentration ratios of the initial compound and the acid, complexes have the structure different from the corresponding aqueous solutions. The substitution reaction of zirconium inorganic ligands when sulfuric acid is added is also of interest. At present, a number of works has been published [2-9] where zirconium oxychloride and hydroxide aqueous solutions with the adding of hydrochloric, sulfuric, and nitric acids along with their mixtures are the objects under study. However, only solid phases which are sequentially precipitated from solutions are described in these works. It was supposed that the solution composition corresponded to the composition of obtained precipitates. Thus, in the systems studied the occurrence of a set of complexes with different structures and with various zirconium and sulfur ratios is supposed. Nevertheless, it is not obvious since the solution composition changes when compounds precipitate. The structure of zirconium complexes directly in solutions is described in this work. As the objects of investigation, zirconium hydroxide and oxychloride are taken.

\section{EXPERIMENTAL}

$\mathrm{ZrOCl}_{2} \cdot 8 \mathrm{H}_{2} \mathrm{O}$ (analytical grade) is used in the work. Zirconium hydroxide is obtained by precipitating from the zirconium oxychloride solution with an ammonia aqueous solution at $65-70^{\circ} \mathrm{C}$ and the constant $\mathrm{pH} 9$. Zirconium sulfate is prepared from the oxychloride solution by the known technique [10].

The following substances were studied: zirconium hydroxide, hydroxide solutions, zirconium oxychloride and sulfate with the listed in Table 1 concentration ratios of zirconium compounds and sulfuric acid. The sample marking indicates the initial compound and the molar concentration ratio for sulfuric acid and zirconium. The concentration of zirconium in solutions is selected in such a way as to provide the maximally wide range within the method potential. The ratio between zirconium and the acid was determined similarly. Initial compounds were dissolved by their thorough mixing with the solvent under normal conditions.

Zirconium oxychloride and sulfate dissolved in water completely; the solution represented a transparent homogeneous liquid. After sulfuric acid was added and the solution was thoroughly stirred, the solution transparency and homogeneity did not change.

TABLE 1. Investigated Solutions

\begin{tabular}{|c|c|c|c|c|c|}
\hline Sample & Initial compound & Dissolvent & $\begin{array}{c}\text { Initial compound } \\
\text { concentration, } \\
\text { mole } / 1\end{array}$ & $\begin{array}{c}\mathrm{H}_{2} \mathrm{SO}_{4} \\
\text { concentration, } \\
\text { mole } / 1\end{array}$ & $\begin{array}{l}\text { Ratio between } \\
\mathrm{H}_{2} \mathrm{SO}_{4} \text { and initial } \\
\text { compound } \\
\text { concentrations }\end{array}$ \\
\hline $\mathrm{ZrO} 95$ & \multirow{5}{*}{$\mathrm{ZrO}_{2} \times 4 \mathrm{H}_{2} \mathrm{O}$} & \multirow[b]{5}{*}{ Solid sample } & \multirow[t]{2}{*}{0.05} & 4.75 & 95 \\
\hline $\mathrm{ZrO} 50$ & & & & 2.38 & 47.46 \\
\hline $\mathrm{ZrO} 30$ & & & 0.15 & 4.75 & 31.67 \\
\hline $\mathrm{ZrO} 10$ & & & 0.25 & 2.38 & 9.52 \\
\hline $\mathrm{ZrO}$ & & & - & 0 & 0 \\
\hline $\mathrm{ZrCl} 40$ & \multirow{5}{*}{$\mathrm{ZrOCl}_{2} \times 8 \mathrm{H}_{2} \mathrm{O}$} & \multirow{5}{*}{$\mathrm{H}_{2} \mathrm{O}$} & 0.1 & 3.8 & 38 \\
\hline $\mathrm{ZrCl} 10$ & & & 0.24 & 2.4 & 10 \\
\hline $\mathrm{ZrCl} 8$ & & & 0.5 & 4 & 8 \\
\hline $\mathrm{ZrCl} 4$ & & & 0.4 & 1.4 & 3.5 \\
\hline $\mathrm{ZrCl}$ & & & 0.5 & 0 & 0 \\
\hline $\mathrm{ZrS}$ & $\mathrm{Zr}\left(\mathrm{SO}_{4}\right)_{2} \times 4 \mathrm{H}_{2} \mathrm{O}$ & $\mathrm{H}_{2} \mathrm{O}$ & 0.5 & $\overline{0}$ & $\overline{0}$ \\
\hline
\end{tabular}


It is known that zirconium hydroxide is poorly water-soluble. When it is dissolved, precipitate peptization and the solution opalescence are observed. When sulfuric acid is added to the solution and under thorough stirring the precipitate dissolved and opalescence disappeared. Also it is known that the presence of large (hundreds of nanometers) makes solutions opalesce. The majority of complexes in the solution would have at that the structure of initial compounds. Let us remind that in our case the opalescence was absent.

X-ray absorption spectra of the zirconium $K$-edge were measured by the standard transmission method [11] at the EXAFS Station of the Siberian Synchrotron Radiation Center (Novosibirsk, Russia). As a radiation source, a VEPP-3 storage ring was used with an electron beam energy of $2 \mathrm{GeV}$ and an average stored current of $80 \mathrm{~mA}$. The spectrometer has a double-crystal cut $\mathrm{Si}(111)$ monochromator and the proportional chambers as detectors. To record EXAFS-spectra, the solutions were placed into a Teflon cuvette with the thickness chosen to obtain the zirconium absorption jump value of $\Delta \mu_{x}$ $\sim 0.8$. For all the samples, the oscillating part $\chi(k)$ of the EXAFS spectrum was analyzed as $k^{3} \chi(k)$ within a wave number range of $k=3.5-12 \AA^{-1}$. In order to determine the structural data, the oscillating part of the absorption coefficient was extracted and spectra modeled with the VIPER program [12].

The standard slot goniometer KRM-1 (Burevestnik, Russia) was used to measure small-angle scattering curves allowing the record in an angle range of $7^{\prime}-9^{\circ}$. The solutions were placed into the dismountable stainless steel cuvettes with lavsan film 15-20 $\mu \mathrm{m}$ thick. The sample thickness was chosen from the absorption ability of the sample material with respect to $\mathrm{Cu} K_{\alpha}$ radiation. The distances tube-sample and sample-receiving slot were $250 \mathrm{~mm}$.

\section{EXPERIMENTAL RESULTS}

Small-angle X-ray scattering. The size distribution of particles is calculated from the small-angle scattering data. It shows that in all solutions the particles with a typical diameter $d$ of the equivalent sphere of an order of 12-18 $\AA$ (Table 2) are observed. The results indicate the predominance of small sized particles. The character of the small-angle scattering curves reveals that the shape of the particles is close to spherical. The similarity of the curves allows the assumption that shapes of the particles are conformable. The equivalent sphere diameter for the particles observed in the solution indicates their polynuclei structure containing several zirconium atoms. The particle size of the mononuclear complex does not exceed 6-7 $\AA$.

EXAFS. Zirconium hydroxide. Fig. 1 illustrates the most characteristic curves of the radial distribution of atoms (RDA) around the zirconium atom for hydroxide solutions at different concentrations of sulfuric acid. Also the RDA curve for the zirconium sulphate aqueous solution is depicted there. Table 3 contains the results of spectra modeling. The

TABLE 2. Results of the Complete Analysis of Small-Angle Scattering Curves

\begin{tabular}{c|c}
\hline Sample & $d, \AA$ \\
\hline ZrO 95 & 15.1 \\
ZrO 50 & 12.2 \\
ZrO 30 & 15.0 \\
ZrO 10 & 14.9 \\
ZrO & 18.2 \\
ZrCl 40 & 15.0 \\
ZrCl 10 & 13.1 \\
ZrCl 8 & 14.9 \\
ZrCl 8, ageing for 8 days & 18.5 \\
ZrCl 4 & 14.1 \\
ZrCl & 15.0 \\
ZrS & 18.4
\end{tabular}




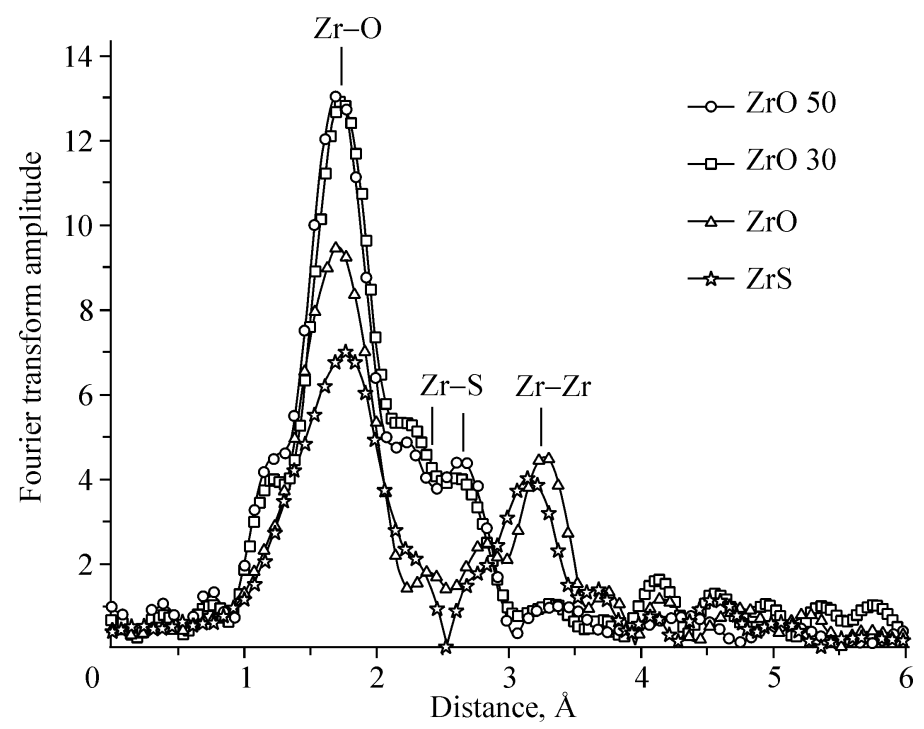

Fig. 1. Radial distribution curves for atoms around $\mathrm{Zr}$ obtained from EXAFS-spectra for samples ZrO 50, ZrO 30, ZrO, and ZrS.

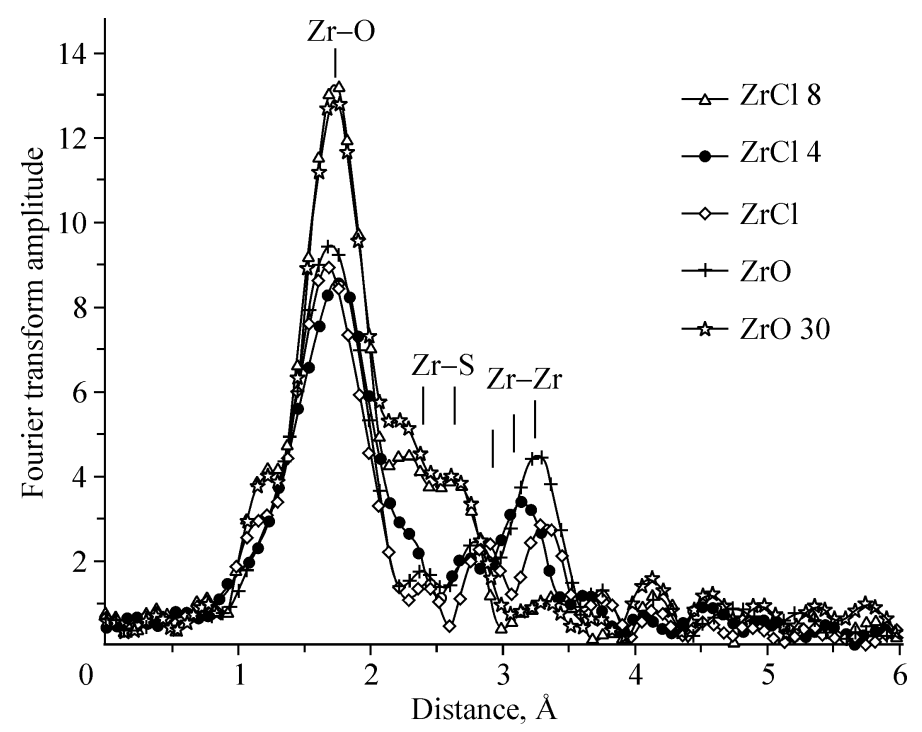

Fig. 2. Curves of the radial distribution of atoms around $\mathrm{Zr}$ obtained from the EXAFS spectra for $\mathbf{Z r C l ~} 8, \mathbf{Z r C l} 4, \mathbf{Z r C l}$, ZrO, and ZrO 30 samples in the presence of sulfuric acid.

assignment of types of the ligands to $\mathrm{Zr}-\mathrm{S}$ or $\mathrm{Zr}-\mathrm{Zr}$ distances was made by comparing the modeling quality, i.e. the coordination factor value for the experimental spectra and their models for each variant.

When sulfuric acid is added to the zirconium hydroxide solution, the $\mathrm{Zr}-\mathrm{Zr}$ distance of $3.6 \AA$ disappears on the radial distribution curve, and the structure of the zirconium ligand surrounding changes. The $\mathrm{Zr}-\mathrm{O}$ distance for these solutions is $2.2 \AA$ with the coordination number 8. Also two distances $\mathrm{Zr}-\mathrm{S} 2.9 \AA$ and $3.15 \AA$ are observed in the zirconium surrounding. The coordination number for these distances is about 3 and 2, respectively, and it changes depending on the concentration ratio for hydroxide and sulfuric acid in the solution.

Zirconium oxychloride. Fig. 2 depicts RDA curves obtained from EXAFS-spectra for aqueous solutions of zirconium oxychloride and hydroxide in the presence of sulfuric acid. The results of spectra modeling are given in Table 3. 
TABLE 3. Results of the EXAFS-spectra Modeling

\begin{tabular}{|c|c|c|c|c|c|c|}
\hline Sample & Atom & Distance, $\AA$ & Coord. number & $\sigma^{2}, \AA^{2}$ & $E_{0}, \mathrm{eV}$ & $R$ Factor, $\%$ \\
\hline ZrO 95 & $\begin{array}{c}\mathrm{Zr}-\mathrm{O} \\
\mathrm{Zr}-\mathrm{S} \\
\mathrm{Zr}-\mathrm{S} \\
\end{array}$ & $\begin{array}{l}2.21 \\
2.88 \\
3.05 \\
\end{array}$ & $\begin{array}{l}7.48 \\
3.35 \\
2.27 \\
\end{array}$ & $\begin{array}{l}0.00732 \\
0.00469 \\
0.01285 \\
\end{array}$ & $\left.\begin{array}{l}1.948 \\
0.049 \\
0.087\end{array}\right\}$ & 19.86 \\
\hline ZrO 50 & $\begin{array}{c}\mathrm{Zr}-\mathrm{O} \\
\mathrm{Zr}-\mathrm{S} \\
\mathrm{Zr}-\mathrm{S} \\
\end{array}$ & $\begin{array}{l}2.22 \\
2.89 \\
3.16 \\
\end{array}$ & $\begin{array}{l}8.13 \\
2.99 \\
1.96 \\
\end{array}$ & $\begin{array}{l}0.00732 \\
0.00469 \\
0.01285 \\
\end{array}$ & $\left.\begin{array}{c}-0.970 \\
0.017 \\
-0.006\end{array}\right\}$ & 23.73 \\
\hline ZrO 30 & $\begin{array}{c}\mathrm{Zr}-\mathrm{O} \\
\mathrm{Zr}-\mathrm{S} \\
\mathrm{Zr}-\mathrm{S} \\
\end{array}$ & $\begin{array}{l}2.21 \\
2.87 \\
3.14 \\
\end{array}$ & $\begin{array}{l}7.71 \\
3.19 \\
1.34 \\
\end{array}$ & $\begin{array}{l}0.00732 \\
0.00469 \\
0.01285 \\
\end{array}$ & $\left.\begin{array}{c}2.792 \\
0.036 \\
-0.008\end{array}\right\}$ & 20.36 \\
\hline ZrO 10 & $\begin{array}{c}\mathrm{Zr}-\mathrm{O} \\
\mathrm{Zr}-\mathrm{S} \\
\mathrm{Zr}-\mathrm{S} \\
\end{array}$ & $\begin{array}{l}2.23 \\
2.89 \\
3.11 \\
\end{array}$ & $\begin{array}{l}7.04 \\
2.47 \\
1.31 \\
\end{array}$ & $\begin{array}{l}0.00732 \\
0.00469 \\
0.01285 \\
\end{array}$ & $\left.\begin{array}{c}0.05 \\
0.063 \\
0.108\end{array}\right\}$ & 23.65 \\
\hline $\mathrm{ZrO}$ & $\begin{array}{l}\mathrm{Zr}-\mathrm{O} \\
\mathrm{Zr}-\mathrm{Zr}\end{array}$ & $\begin{array}{l}2.22 \\
3.61 \\
\end{array}$ & $\begin{array}{l}7.12 \\
1.56 \\
\end{array}$ & $\begin{array}{l}0.00935 \\
0.00388 \\
\end{array}$ & $\left.\begin{array}{c}4.172 \\
-0.100\end{array}\right\}$ & 20.21 \\
\hline $\mathrm{ZrCl} 40$ & $\begin{array}{c}\mathrm{Zr}-\mathrm{O} \\
\mathrm{Zr}-\mathrm{S} \\
\mathrm{Zr}-\mathrm{S} \\
\end{array}$ & $\begin{array}{l}2.22 \\
2.90 \\
3.13 \\
\end{array}$ & $\begin{array}{l}8.21 \\
3.54 \\
1.57 \\
\end{array}$ & $\begin{array}{l}0.00646 \\
0.00509 \\
0.00574 \\
\end{array}$ & $\left.\begin{array}{l}0.060 \\
0.093 \\
0.011\end{array}\right\}$ & 26.73 \\
\hline ZrCl 10 & $\begin{array}{c}\mathrm{Zr}-\mathrm{O} \\
\mathrm{Zr}-\mathrm{S} \\
\mathrm{Zr}-\mathrm{S} \\
\end{array}$ & $\begin{array}{l}2.21 \\
2.90 \\
3.17 \\
\end{array}$ & $\begin{array}{l}8.13 \\
3.42 \\
1.00 \\
\end{array}$ & $\begin{array}{l}0.00700 \\
0.00591 \\
0.00520 \\
\end{array}$ & $\left.\begin{array}{c}0.141 \\
-0.002 \\
0.014\end{array}\right\}$ & 18.46 \\
\hline ZrCl 8 & $\begin{array}{c}\mathrm{Zr}-\mathrm{O} \\
\mathrm{Zr}-\mathrm{S} \\
\mathrm{Zr}-\mathrm{S} \\
\end{array}$ & $\begin{array}{l}2.20 \\
2.89 \\
3.12 \\
\end{array}$ & $\begin{array}{l}7.30 \\
3.36 \\
1.35 \\
\end{array}$ & $\begin{array}{l}0.00630 \\
0.00500 \\
0.00551 \\
\end{array}$ & $\left.\begin{array}{l}0.121 \\
0.076 \\
0.011\end{array}\right\}$ & 16.72 \\
\hline $\begin{array}{c}\mathrm{ZrCl} 8 \\
\text { ageing for } 8 \text { days }\end{array}$ & $\begin{array}{c}\mathrm{Zr}-\mathrm{O} \\
\mathrm{Zr}-\mathrm{S} \\
\mathrm{Zr}-\mathrm{S} \\
\end{array}$ & $\begin{array}{l}2.23 \\
2.93 \\
3.18 \\
\end{array}$ & $\begin{array}{l}7.74 \\
3.58 \\
1.25 \\
\end{array}$ & $\begin{array}{l}0.00746 \\
0.00513 \\
0.00500 \\
\end{array}$ & $\left.\begin{array}{l}0.049 \\
0.032 \\
0.009\end{array}\right\}$ & 20.05 \\
\hline ZrCl 4 & $\begin{array}{l}\mathrm{Zr}-\mathrm{O} \\
\mathrm{Zr}-\mathrm{Zr} \\
\end{array}$ & $\begin{array}{l}2.22 \\
3.56 \\
\end{array}$ & $\begin{array}{l}7.17 \\
0.86 \\
\end{array}$ & $\begin{array}{l}0.01016 \\
0.00225 \\
\end{array}$ & $\left.\begin{array}{l}0.473 \\
0.006\end{array}\right\}$ & 31.67 \\
\hline $\mathrm{ZrCl}$ & $\begin{array}{l}\mathrm{Zr}-\mathrm{O} \\
\mathrm{Zr}-\mathrm{Zr} \\
\mathrm{Zr}-\mathrm{Zr}\end{array}$ & $\begin{array}{l}2.21 \\
3.39 \\
3.62 \\
\end{array}$ & $\begin{array}{l}6.97 \\
0.59 \\
1.06 \\
\end{array}$ & $\begin{array}{l}0.00960 \\
0.00362 \\
0.00408 \\
\end{array}$ & $\left.\begin{array}{l}0.044 \\
0.028 \\
0.036\end{array}\right\}$ & 18.88 \\
\hline $\mathrm{ZrS}$ & $\begin{array}{l}\mathrm{Zr}-\mathrm{O} \\
\mathrm{Zr}-\mathrm{Zr}\end{array}$ & $\begin{array}{l}2.22 \\
3.57\end{array}$ & $\begin{array}{l}6.25 \\
1.76\end{array}$ & $\begin{array}{l}0.01087 \\
0.00510\end{array}$ & $\left.\begin{array}{c}0.008 \\
-0.002\end{array}\right\}$ & 30.19 \\
\hline
\end{tabular}

When sulfuric acid is added into the zirconium oxychloride solution, the maxima on RDA curves, corresponding to $\mathrm{Zr}-\mathrm{Zr}$ distances of $3.4 \AA$ and $3.6 \AA$ typical of individual oxychloride, disappear as the acid concentration increases. The same occurs for hydroxide. At the same time, a gradual transformation of complexes is observed in the oxychloride solution. The radial distribution curve for ZrCl 4 sample manifests it. $\mathrm{Zr}-\mathrm{S}$ distances of $2.9 \AA$ and $3.15 \AA$ begin to appear on it, and peaks assigned to $\mathrm{Zr}-\mathrm{Zr}$ distances of $3.4 \AA$ and $3.6 \AA$ decrease in intensity and merge into one wide peak which then disappears. It should be noted that the RDA curves for oxychloride and hydroxide solutions with the similar molar ratio between sulfuric acid and zirconium practically coincide.

RDA curves for ZrCl 8 sample (Fig. 3) which was aged under normal conditions for 8 days illustrate the absence of considerable changes in the zirconium local environment. According to the data of small-angle X-ray scattering, an insignificant increase in the size of particles in the solution is observed (Table 2). It is most likely to be connected with the aggregation processes. 


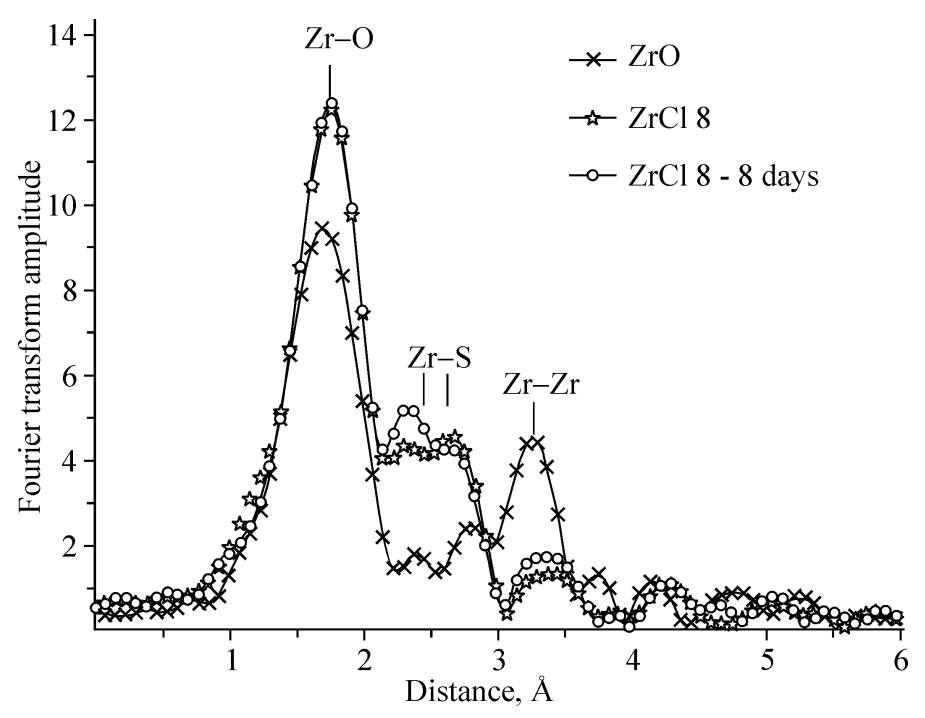

Fig. 3. Curves of the radial distribution of atoms around $\mathrm{Zr}$ obtained from the EXAFS spectra for $\mathrm{ZrO}, \mathrm{ZrCl} \mathrm{8}$, and $\mathrm{ZrCl} 8$ samples aged for 8 days.

\section{RESULTS AND DISCUSSION}

Initial structures of zirconium hydroxide and oxychloride contain in their base the plane square of zirconium ions bound by double bridge hydroxide groups. The $\mathrm{Zr}-\mathrm{Zr}$ distance in such tetramers is close to $3.6 \AA$. Fig. 1 depicts the RDA curves for the hydroxide and zirconium sulfate aqueous solution. In both samples $\mathrm{Zr}-\mathrm{Zr}$ distances are close to $3.6 \AA$ and the coordination numbers for these distances are 1.6 and 1.8 respectively. Calculated effective coordination numbers for $\mathrm{Zr}-\mathrm{O}$ distances are 7 and 6 that is smaller than 8 calculated by the diffuse X-ray scattering method [13].

The coordination number 8 of the zirconium(IV) ligand surrounding is maximal and is observed only for the highsymmetry ligand surrounding of zirconium. The oxygen surrounding of $\mathrm{Zr}$ for individual solutions is less symmetrical. It is known that the asymmetry of the surrounding with several $\mathrm{Zr}-\mathrm{O}$ distances results in the decrease of the effective coordination number calculated by the EXAFS method [14].

Zirconium hydroxide. Two Zr-S distances $(2.9 \AA$ and $3.15 \AA)$ in the EXAFS spectra for zirconium hydroxide aqueous solutions with sulfuric acid added can indicate the presence of two different complexes or one complex with a complicated structure in the solution. The first case is impossible because there is only one $\mathrm{Zr}-\mathrm{O}$ distance and the symmetry of the zirconium oxygen surrounding is rather high. So we have to deal with a complex of a complicated structure. Then the longest $\mathrm{Zr}-\mathrm{S}$ distance $(3.15 \AA)$ relates to sulfur atoms of sulfate groups and the shortest one $(2.9 \AA)$ to sulfur atoms of terminal sulfate groups. The occurrence of bridge sulfate groups binding zirconium atoms (according to the small-angle scattering data, there are several of them in the particle) does not contradict to the absence of $\mathrm{Zr}-\mathrm{Zr}$ distances in the spectra, since in such a way of coordination it exceeds $6 \AA$ that oversteps the limits of distances detected by EXAFS. For ZrO 30 and ZrO 10 samples with the molar concentration ratio for sulfuric acid and zirconium hydroxide of 30 and 10 respectively, the coordination number for the long distance $\mathrm{Zr}-\mathrm{S}(3.15 \AA)$ equals $4 / 3$. This situation is realized for the chain of three zirconium atoms linked by two bridges of sulfate groups. Around the central zirconium atom there will be two sulfur atoms from the bridge sulfate group, while two outermost zirconium atoms will have one sulfur atom per each.

For ZrO 95 и ZrO 50 samples with the molar concentration ratio for sulfuric acid and zirconium hydroxide of $\sim 90$ and 50 respectively, the coordination number for the long distance $\mathrm{Zr}-\mathrm{S}(3.15 \AA)$ equals 2 . This corresponds to the closed structure of the complex, and zirconium atoms in it are also bonded by sulfate groups. According to small-angle scattering, the size of particles in the solution for these samples is equal to $12.2 \AA$ and $15.1 \AA$ respectively (Table 2). Particles of these sizes can have the structure of a closed trimer. 


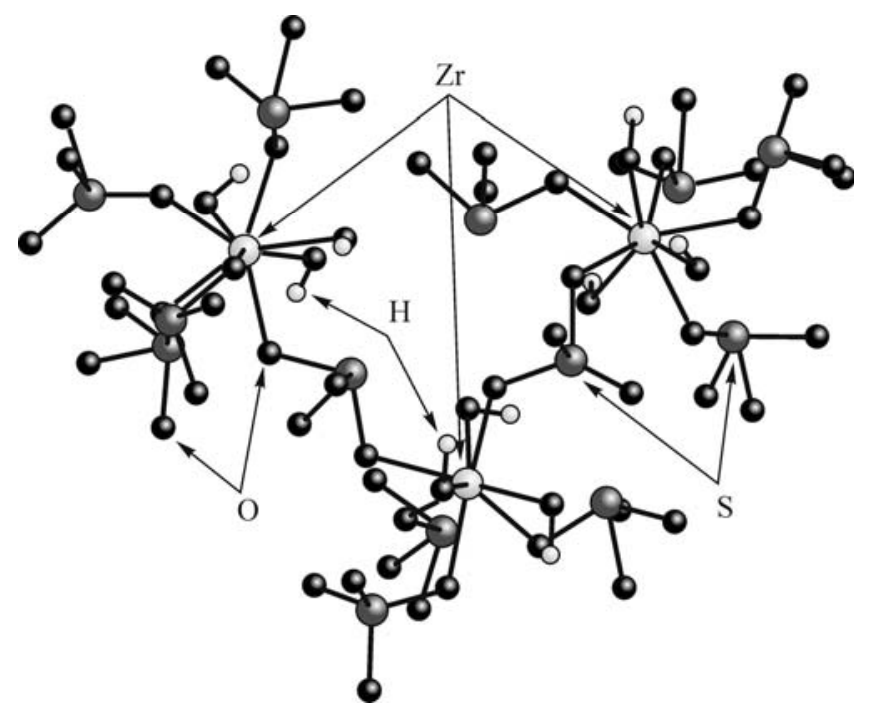

Fig. 4. Structure of an open trimer.

The coordination number for the neighboring sulfur atom of terminal sulfate groups ( $2.9 \AA$ ) for $\mathbf{Z r O ~ 9 5 , ~ Z r O ~ 5 0 , ~}$ ZrO 30, ZrO 10 samples is $\sim 3$ (Table 3). So there are about 3-4 terminal sulfate groups coordinated to each zirconium atom. There are three terminal sulfate groups coordinated to the zirconium central atom in the open trimer. According to the data obtained, there are four analogous sulfate groups coordinated to terminal zirconium atoms in the open trimer. For the closed trimer, the number of terminal sulfate groups is three. Since the zirconium coordination number with respect to oxygen equals eight (sulfate groups are coordinated to zirconium through oxygen), it is obvious that to each zirconium atom yet another three terminal hydroxyl groups are coordinated, as the total number of bridge and terminal sulfate groups remains constant for all complex configurations. It is not improbable that when the solution acidity changes, sulfate groups can substitute (in a minor quantity) for hydroxyl groups in the complexes, however it will not affect the coordination number with respect to oxygen.

Zirconium oxychloride. For zirconium oxychloride solutions, the same picture as in the previous case is observed: curves for oxychloride and hydroxide solutions with sulfuric acid added virtually coincide. This fact indicates that the structure of complexes coincides. The coordination number for the long distance $\mathrm{Zr}-\mathrm{S}$ (3.15 $\AA$ ) about $4 / 3$ is observed for samples ZrCl 10 and $\mathrm{ZrCl} 8$ with the molar concentration ratio for sulfuric acid and the initial compound of 10 and 8 respectively. Therefore, the complex in these samples has the structure of an open chain of three zirconium atoms (Fig. 4). For ZrCl 40 sample with a molar ratio of about 40 c.n. with respect to the remote sulfur atom ( $3.15 \AA$ ) approaches to two that indicates the predominance of particles formed by complexes with the structure of closed trimer in the solution (Fig. 5).

The situation with the coordination number with respect to the near sulfur atom of terminal sulfate groups (2.9 $\AA$ ) for $\mathrm{ZrCl} \mathrm{40,} \mathrm{ZrCl} \mathrm{10}$, and $\mathrm{ZrCl} 8$ samples is similar to that for the zirconium hydroxide aqueous solution in the presence of sulfuric acid. Three terminal sulfate groups are coordinated to each zirconium atom except the terminal zirconium atoms from the open trimer: there are four terminal sulfate groups coordinated to each of them. As in the case of zirconium hydroxide, the zirconium coordination number with respect to oxygen equals 8 , and there are three more terminal hydroxyl groups coordinated to each zirconium atom.

When keeping (ageing) ZrCl 8 sample at the room temperature and atmospheric pressure in a sealed cuvette for 8 days, a significant change in the zirconium local environment is not observed that indicates the preservation of the complex structure. However, an insignificant increase in the size of particles in the solution occurs caused by aggregation of complexes.

As it has been mentioned, the presence of both the initial oxychloride complex and substituted by sulfuric acid is observed for ZrCl 4 sample with a molar ratio of sulfuric acid and zirconium oxychloride of 4 . It can be concluded that the amount of sulfuric acid added to $\mathbf{Z r C l} 4$ sample is not enough for the complete substitution of ligands. 


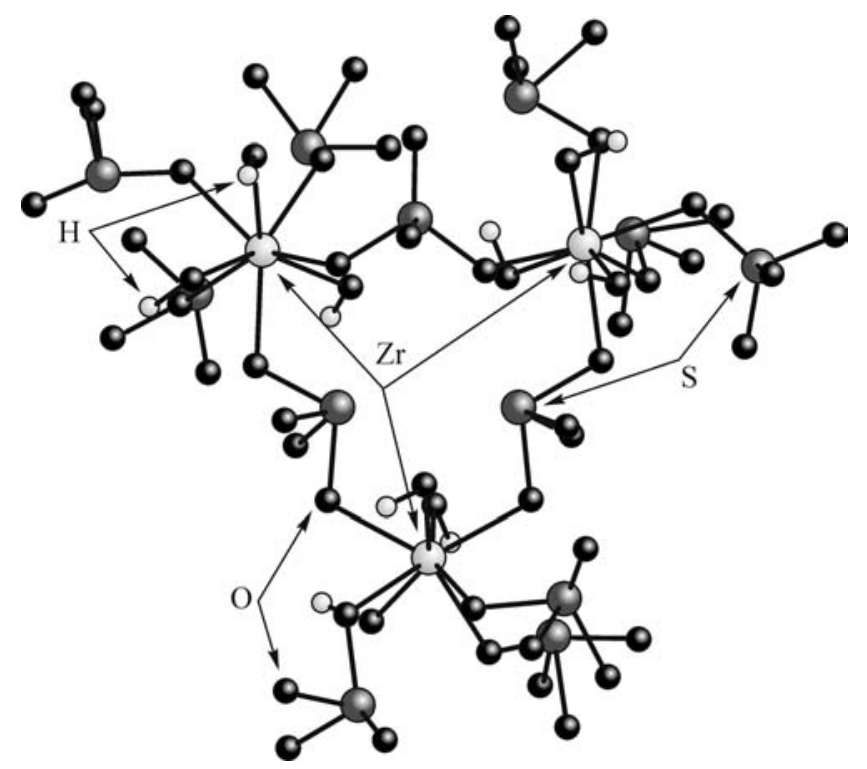

Fig. 5. Structure of a closed trimer.

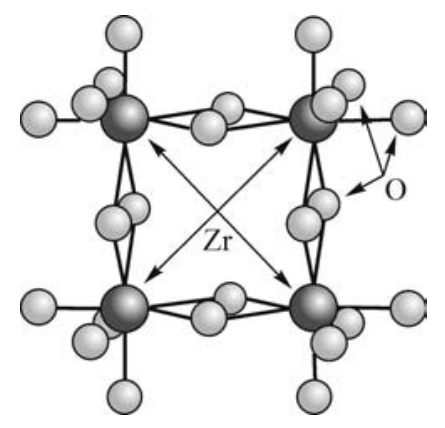

Fig. 6. Structure of the main structural unit of complexes in zirconium oxychloride and hydroxide solutions.

Common and different features in the structure of complexes. significant differences in the structure of complexes in the individual zirconium sulphate and hydroxide solutions with substituted ligands can be explained by the effect of the high acidity of the solutions and by the peculiarities of the substitution process.

The main structural unit of the complex for zirconium oxychloride and hydroxide solutions, as well as for zirconium sulfate, is the square with zirconium atoms bound by the double oxygen bridges (Fig. 6). When sulfuric acid is added, the breakage of bridge bonds occurs and substitution of a part of hydroxyl ligands by sulfate groups takes place, and so the open chain of three zirconium atoms linked by the bridges of sulfate groups is formed (Fig. 4). When the sulfuric acid concentration is increasing, the chain en closes with one more hydroxyl group leaving (Fig. 5).

\section{CONCLUSIONS}

According to the data obtained, the complex in the zirconium hydroxide aqueous solution with the sulfuric acid added can be described as an open (Fig. 4) or a closed trimer (Fig. 5) in which zirconium atoms are connected by sulfate groups. Apart from the bridge sulfate groups, there are three terminal sulfate groups and three terminal hydroxyl groups per each zirconium atom in the complex structure. 
The shortest $\mathrm{Zr}-\mathrm{Zr}$ distance in the given model for the complex is longer than $6 \AA$. According to calculations, the averaged size of such particle in the solution is about $15 \AA$, that is confirmed by the small-angle scattering data.

The complex transforms in oxychloride and hydroxide solutions in the presence of sulfuric acid. The complex whose main structural unit is a tetramer in the form of a square with zirconium atoms linked by double oxygen bridges (Fig. 6) transforms to an open trimer (Fig. 4) which has a tendency to enclosing at the increase of the sulfuric acid concentration (Fig. 5).

The ageing of a sample under the normal conditions for a long time does not result in the change of the complex structure, though it promotes aggregation of particles in the solution.

This work was partially supported by the CRDF (grant NO-008-X1), INTAS (grant No. 00-0863), and RFBR (grant No. 05-03-32326).

\section{REFERENCES}

1. V. V. Kanazhevskii, B. N. Novgorodov, V. P. Shmachkova, et al., Mendeleev Commun., 211/212 (2001).

2. A. K. Kirakosyan and I. V. Tanaev, Zh. Neorg. Khim., 6, No. 8, 1808-1812 (1961).

3. Ya. G. Goroshchenko and T. P. Spasibenko, ibid., 7, No. 5, 1159-1168 (1962).

4. S. M. Flaks and I. A. Sheka, Zh. Prikl. Khim., 42, No 8, 1747-1754 (1969).

5. V. K. Kozlova, L. G. Nekhamkin, and L. M. Zaitsev, Zh. Neorg. Khim., 14, No. 3, 798-802 (1969).

6. L. G. Nekhamkin, N. M. Kolpachkova, E. G. Kharitonova, and I. A, Kondrashova ibid., 27, No. 10, 266/267 (1982).

7. L. G. Nekhamkin, Yu. A. Tsylov, A. M. Reznik, et al., Izv. Vyssh. Uchebn. Zaved., Tsv. Metallurgiya, No. 2, 73-76 (1984).

8. M. M. Godneva, R. F. Okhrimenko, and A. E. Kirichenko, Zh. Neorg. Khim., 31, No. 2, 360-364 (1986).

9. M. M. Godneva, D. L. Motov, R. F. Okhrimenko, and V. Ya. Kuznetsov, ibid., 39, No. 5, 740-742 (1994).

10. Handbook of Inorganic Synthesis, 4, Mir, Moscow (1985).

11. D. I. Kochubey, Yu. A. Babanov, K. I. Zamaraev, et al., X-ray Spectroscopic Method for the Determination of the Structure of Amorphous Bodies: EXAFS-spectroscopy [in Russian], Nauka, Novosibirsk (1988).

12. K. V. Klementev, Nucl. Instr. Meth. Phys. Res. A, 448, 299 (2000).

13. M. Aberg, Acta Chem. Scand., B31, 171-181 (1977).

14. M. V. Tsodikov, O. V. Bukhtenko, O. G. Ellert, et al., J. Mater. Science, 30, 1087-1094 (1995). 